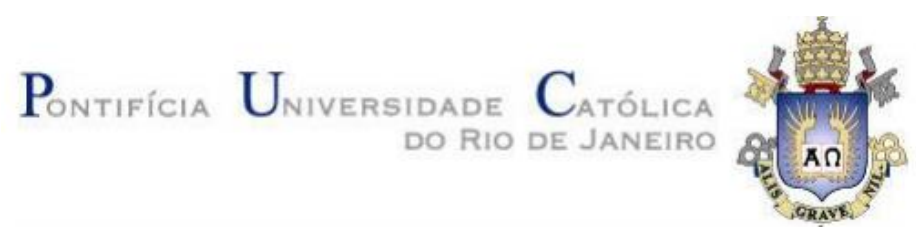

Roberto Bandarra Marques Pires

\title{
Ofertas Públicas Primárias de empresas investidas por fundos de private equity no Brasil: performance $e$ características
}

\begin{abstract}
Dissertação de Mestrado
Dissertação apresentada como requisito parcial para obtenção do grau de Mestre pelo Programa de Pós-Graduação em Macroeconomia e Finanças do Departamento de Economia do Centro de Ciências Sociais da PUC-Rio.
\end{abstract}

Orientador: Prof. Ruy Monteiro Ribeiro

Rio de Janeiro

Julho de 2017 


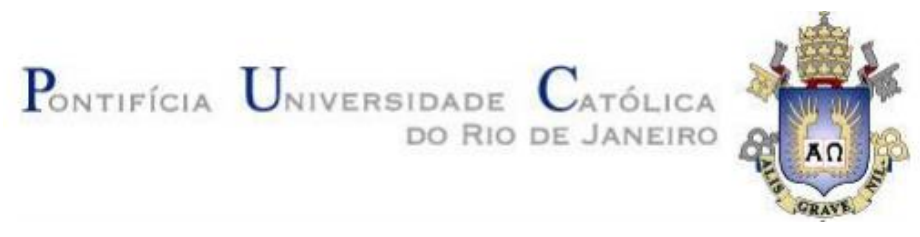

Roberto Bandarra Marques Pires

\title{
Ofertas Públicas Primárias de empresas investidas por fundos de Private Equity no Brasil: performance e características
}

\begin{abstract}
Dissertação apresentada como requisito parcial para obtenção do grau de Mestre pelo Programa de PósGraduação em Macroeconomia e Finanças do Departamento de Economia do Centro de Ciências Sociais da PUC-Rio. Aprovada pela Comissão Examinadora abaixo assinada.
\end{abstract}

Prof. Ruy Monteiro Ribeiro Orientador

Departamento de Economia - PUC-Rio

Prof. Luiz Brandão Departamento de Administração - PUC-Rio

Prof. Patrick Behr FGV-RJ

Prof. Augusto Cesar Pinheiro da Silva Vice-Decano Setorial de Pós-Graduação do Centro de Ciências Sociais - PUC-Rio

Rio de Janeiro, 17 de julho de 2017 
Todos os direitos reservados. É proibida a reprodução total ou parcial do trabalho sem autorização da universidade, do autor e do orientador.

\section{Roberto Bandarra Marques Pires}

Graduado em Economia pela FGV-RJ em 2013. Cursou o Mestrado Profissional em Macroeconomia e Finanças, com ênfase em Finanças, pelo Departamento de Economia da PUC-Rio

Ficha Catalográfica

\section{Pires, Roberto Bandarra Marques}

Ofertas Públicas Primárias de empresas investidas por fundos de private equity no Brasil: performance e características / Roberto Bandarra Marques Pires; orientador: Ruy Monteiro Ribeiro - 2017

43 f.: il. color.; $30 \mathrm{~cm}$

Dissertação (mestrado) - Pontifícia Universidade Católica do Rio de Janeiro, Departamento de Economia, 2017.

Inclui bibliografia

1. Economia - Teses. 2. Oferta Pública Primária (IPO). 3. Private Equity. 4. Performance. 5. Governança. I. Ribeiro, Ruy Monteiro. II. Pontifícia Universidade Católica do Rio de Janeiro. Departamento de Economia. III. Título.

CDD: 330 


\section{Agradecimentos}

Agradeço ao Ruy Ribeiro pela orientação, confiança e incentivo durante todo este processo, e aos membros da banca Luiz Brandão e Patrick Behr pelos comentários. Estendo meus agradecimentos também a todos os professores pelos ensinamentos e dedicação, e à equipe administrativa do departamento pelo apoio. Um abraço especial aos meus amigos e à minha família por toda a torcida e ajuda durante a difícil jornada que se encerra nesta dissertação. Dedico este trabalho aos meus pais, que me deram todo o suporte para sempre buscar o aprendizado. 


\section{Resumo}

Pires, Roberto Bandarra Marques; Ribeiro, Ruy Monteiro. Ofertas Públicas Primárias de empresas investidas por fundos de Private Equity no Brasil: performance e características. Rio de Janeiro, 2017. 43p. Dissertação de Mestrado - Departamento de Economia, Pontifícia Universidade Católica do Rio de Janeiro.

Esta Dissertação apresenta uma análise de retornos e características das emissões primárias de capital (IPO) realizadas na BM\&FBovespa no período de 10 anos compreendido entre 2006 e 2015. Analisamos a relação entre as características de uma empresa no momento de sua abertura de capital e a sua performance no primeiro ano na bolsa contra os pares da bolsa e de seu setor. Além disso, é analisada a influência do investimento por um fundo de Private Equity na formação dessas características. São utilizados dados financeiros e de governança para a construção das variáveis. Podemos observar que empresas investidas por fundos de private equity apresentaram retornos inferiores aos das empresas que não tinham esse tipo de investidor, exceto quanto os fundos mantiveram seus investimentos após a abertura de capital. Além disso, as investidas de fundos de private equity apresentaram melhores níveis de governança, maior grau de alavancagem e menores múltiplos de precificação no momento de suas ofertas primárias.

\section{Palavras-chave}

Oferta pública primária (IPO); Private Equity; Performance; Governança 


\section{Abstract}

Pires, Roberto Bandarra Marques; Ribeiro, Ruy Monteiro (Advisor). Private Equity Backed IPOs in Brazil: Performance and Characteristics. Rio de Janeiro, 2017. 43p. Dissertação de Mestrado Departamento de Economia, Pontifícia Universidade Católica do Rio de Janeiro.

This dissertation presents an analysis of the returns and characteristics of the Initial Public Offerings (IPO) performed at the BM\&FBovespa over a period of 10 years between 2006 and 2015. We analyze the relationship between the characteristics of a company at the time of its IPO and its performance in the first year of trading in the stock exchange against their stock market peers and their industry. In addition, the influence of the investment by a Private Equity fund on the construction of these characteristics is analyzed. Financial and governance data are used to construct the variables. We can observe that companies invested by private equity funds presented lower returns than companies that did not have this type of investor, except when the funds kept their shares after the IPO. In addition, private equity fund's investee companies presented better levels of governance, higher leverage, and lower pricing multiples at the time of their primary offerings.

\section{Keywords}

Initial Public Offering; Private Equity; Performance; Governance 


\section{Sumário}

1 Introdução 10

2 Base de Dados 14

3 Metodologia e Resultados $\quad 17$

4 Estimação do Modelo 28

5 Conclusões 40

6 Referências bibliográficas $\quad 42$ 


\section{Lista de Figuras}

Figura 1.1: Retorno no $1^{\circ}$ ano de Negociações 12

Figura 2.1: Valor das ofertas por tipo de financiamento 15

Figura 3.1: Emissões por Setor 21

Figura 3.2: Tamanho das ofertas por setor 21

Figura 4.1: Valor das ofertas por tipo de financiamento 36 


\section{Lista de Tabelas}

Tabela 1.1: Emissões Primárias de Capital 11

Tabela 3.1: Retorno e CAR no primeiro ano de negociações 18

Tabela 3.2: Outliers (CAR <> 50\%) na série do CAR 19

Tabela 3.3: Concentração setorial das ofertas primárias de capital 20

Tabela 3.4: CAR Setorial no $1^{\circ}$ ano de negociações 22

Tabela 3.5: Quantidade de emissões e CAR separados por setores 23

Tabela 3.6: Retorno e CAR no primeiro dia de negociações 26

Tabela 3.7: Características qualitativas no momento da oferta primária 27

Tabela 4.1: Regressão linear do CAR no primeiro ano de negociações 29

Tabela 4.2: Regressão linear do CAR Setorial no primeiro ano de negociações

Tabela 4.3: Regressão linear do CAR no primeiro dia de negociações

Tabela 4.4: Regressão linear das características no momento da oferta primária

Tabela 4.5: Regressão linear das características no momento da oferta primária incluindo dummies para os setores de Consumo e Financeiro 38 


\section{Introdução}

Nos últimos anos, diversos estudos e matérias internacionais e nacionais estudaram os investimentos realizados por fundos de Private Equity, sob óticas positivas e negativas. Alguns ressaltam a capacidade desta indústria de gerar retornos acima do mercado, enquanto outros atentam para as características específicas deste tipo de investimento, como por exemplo os níveis de alavancagem e governança das empresas investidas.

No cenário brasileiro, esta é uma indústria que carrega reputação de elevar consideravelmente o valor de seus investimentos, obtendo retornos para os investidores envolvidos em períodos relativamente curtos de tempo.

Concomitantemente, a bolsa brasileira carrega a fama de apresentar retornos inferiores aos muitas vezes encontrados em investimentos de renda fixa no país, gerando baixa confiança e afastando o investidor médio do mercado de capitais, que, por conseguinte acaba fazendo com que muitas empresas desconsiderem a abertura de capital na bolsa como uma forma viável de financiamento.

O objetivo deste trabalho é fazer, através da análise de emissões primárias de capital realizadas na BM\&FBovespa, um estudo dos retornos de investimentos realizados por empresas de private equity em comparação ao restante do mercado e, assim, testar o impacto dos fundos como indicadores de retornos futuros para seus investimentos.

Além disso, analisa-se o papel dos fundos como geradores de valor para seu portfólio de empresas investidas, testando a sua influência em aspectos qualitativos como governança, estrutura de capital e precificação de seus investimentos.

Para trazer esta análise à conjuntura brasileira, é utilizada uma base de dados de 97 emissões primárias de capital (IPO) realizadas na BM\&FBovespa entre janeiro de 2006 e dezembro de 2015. 
Tabela 1.1: Emissões Primárias de Capital, 2006-2015

\begin{tabular}{|c|c|c|c|c|c|c|}
\hline & \multicolumn{3}{|c|}{ Emissões Primárias de Capital } & \multicolumn{3}{|c|}{ Tamanho Médio da Emissão (R\$̦ mi) } \\
\hline & $\mathrm{PE}$ & Não-PE & Total & $\mathrm{PE}$ & Não-PE & Total \\
\hline 2006 & 9 & 6 & 15 & 260 & 929 & 527 \\
\hline 2007 & 26 & 13 & 39 & 422 & 1,020 & 622 \\
\hline 2008 & 2 & 2 & 4 & 1,710 & 2,025 & 1,867 \\
\hline 2009 & 2 & 3 & 5 & 1,833 & 6,834 & 4,834 \\
\hline 2010 & 3 & 7 & 10 & 295 & 1,379 & 1,054 \\
\hline 2011 & 7 & 2 & 9 & 615 & 1,020 & 705 \\
\hline 2012 & 1 & 2 & 3 & 100 & 1,930 & 1,320 \\
\hline 2013 & 2 & 8 & 10 & 112 & 2,129 & 1,726 \\
\hline 2014 & 0 & 1 & 1 & - & 363 & 363 \\
\hline 2015 & 0 & 1 & 1 & - & 603 & 603 \\
\hline Total & 52 & 45 & 97 & 535 & 1,823 & 1,362 \\
\hline
\end{tabular}

É inegável o arrefecimento do mercado de emissões primárias de capital: nos 5 primeiros anos da amostra analisada (2006 a 2010), são 73 IPOs (42 investidas de fundos de private equity) com tamanho médio de $\mathrm{R} \$ 1.780,8$ milhões; já nos 5 anos seguintes (2011 a 2015), são 24 ofertas (10 investidas de fundos de private equity) com tamanho médio de R $\$ 943,4$ milhões.

Entretanto, a diferença de retornos no primeiro ano de mercado não é tão significativa: as ofertas ocorridas nos 5 primeiros anos têm média de 13.72\%, enquanto as dos 5 seguintes têm retorno médio de 10,93\%.

Figura 1.1: Retorno no $1^{\mathrm{o}}$ ano de Negociações, 2006-2015 


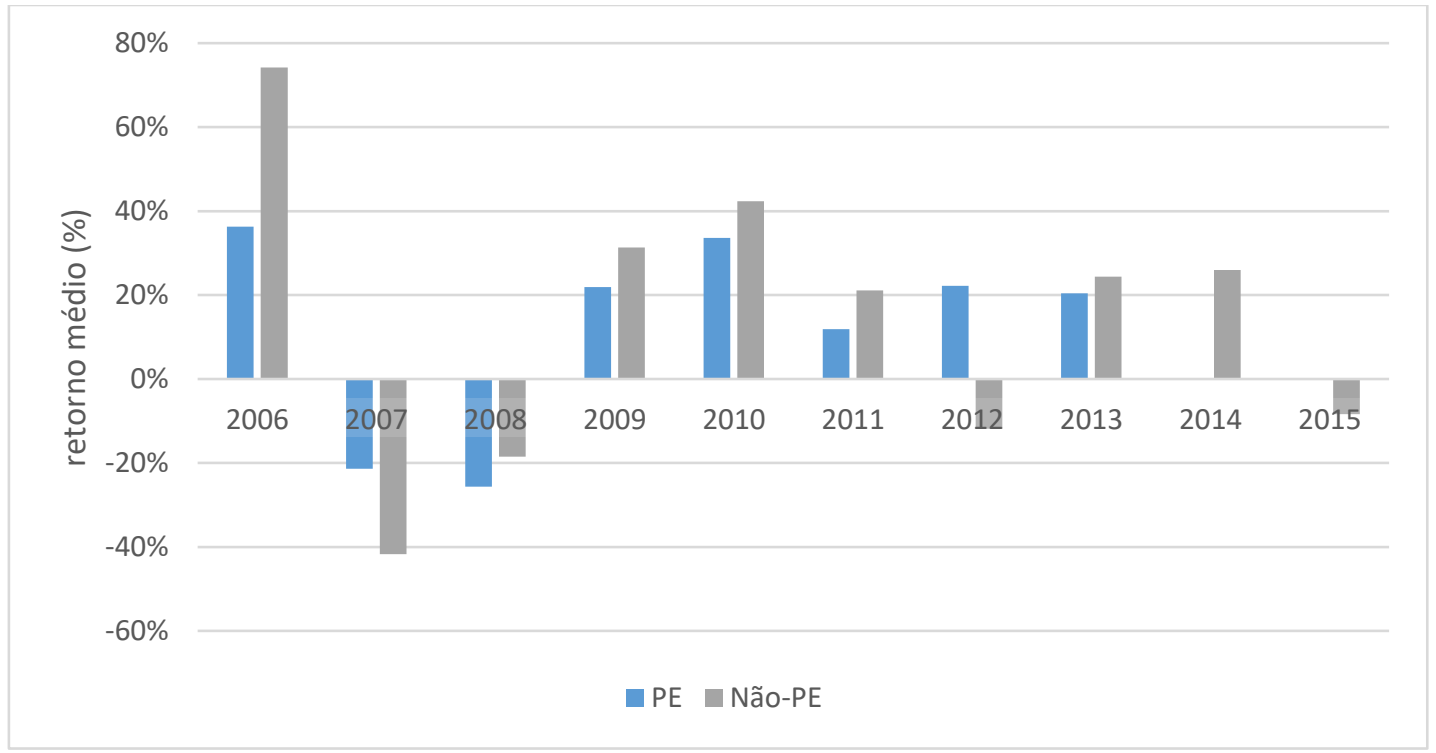

A literatura internacional é relativamente nova na análise dos retornos. Megginson e Weiss (1991) tratam dos retornos de IPOs de empresas administradas por fundos de venture capital em seu primeiro dia de negociação, que tendem a ser menores que o mercado. Hogan, Olson e Kish (2001) e Lee e Wahal (2004) chegam à mesma conclusão mas para um grupo de empresas que voltaram ao mercado de capitais após uma aquisição alavancada (LBO).

Levis (2010) analisa o retorno após 3 anos de negociação de IPOs realizados na bolsa de Londres entre 1992 e 2005 e conclui que as emissões feitas por investidas de fundos de Private Equity apresentam retornos maiores que o mercado e são em médias maiores e se concentram predominantemente em industrias relacionadas a bens de consumo.

Minardi, Ferrari e Tavares (2013) analisam os retornos de 1 ano de IPOs realizados entre janeiro de 2004 e junho de 2008 na BM\&FBovespa, dividindo a amostra entre 2004-2006 e 2007-2008, e concluem que IPOs de empresas investidas por fundos de Private Equity apresentam retornos superiores em ambos os períodos, apesar de não terem ficado imunes à crise de 2008. Os trabalhos de Tavares e Minardi (2010), Bourrat, Wolff e Lopez de Silanes (2013) e Lammi (2016) também foram estudados.

Em comum na literatura é a questão da geração de valor, que continua aberta. Os maiores retornos, segundo é debatido, poderiam ser explicados pela seleção de 
empresas com maiores padrões de governança ou de uma melhor escolha do momento de abertura do capital pelos fundos.

Tais questões implicam, por exemplo, que uma maior profissionalização dos comitês executivos das empresas brasileiras poderia alterar os resultados encontrados anteriormente. Ou que os fundos poderiam passar a acertar menos na escolha do momento de abertura de capital de suas investidas.

Com esse trabalho, analisando as ofertas entre 2006 e 2015, será feita uma atualização dos dados encontrados na literatura, e, ao analisar dados qualitativos das emissões, poderá contribuir com a questão da geração de valor por fundos de private equity para com suas empresas investidas. 


\section{Base de Dados}

A base de dados escolhida foi o total de emissões primárias de ações na BM\&FBovespa de 01/01/2006 até 31/12/2015. O intervalo foi assim selecionado de forma a tentar ampliar o escopo de dados e diluir os efeitos da crise de 2008, que teve impactos visíveis nos mercados globais de ações também em 2009 e 2010.

Como índice de mercado, para balizar as comparações, foi escolhido o Índice Bovespa (ibovespa), uma carteira teórica de ativos que visa representar o desempenho médio dos ativos de maior negociabilidade e representatividade do mercado de ações brasileiro.

Para analisar de forma amplificada as características das empresas e de suas ofertas, foram catalogadas as seguintes informações:

Sobre a oferta: data da emissão; tamanho da oferta; performance no $1^{\circ}$ dia de negociação na bolsa; e performance no $1^{\circ}$ ano de negociação.

Sobre a empresa: presença de fundos de private equity dentre os acionistas no momento da emissão (PE ou Não-PE); Nível de Governança na BM\&FBovespa; Número de Diretores Independentes no Conselho de Administração; Grau de Alavancagem (Dívida Líquida/EBITDA); e Nível de Precificação (Enterprise Value/EBITDA; e Price-to-Book).

Foram utilizados como fontes de dados para consulta e verificação o terminal do Bloomberg e os bancos de dados disponíveis nos sites da BM\&FBovespa, Abvcap (Associação Brasileira de Private Equity e Venture Capital) e CVM (Comissão de Valores Mobiliários).

IPOs considerados "PE Backed" são aqueles em que a empresa emissora tinha dentre seus acionistas algum fundo de investimentos de private equity. A base de dados foi obtida primariamente no terminal do Bloomberg e conferida manualmente, devido ao pouco acesso a informações sobre investimentos nesse setor. 
Quando constatado que o fundo desfez sua posição no momento da oferta, fica configurado um "PE Exit", ao passo que quando o mesmo mantém participação na empresa, é considerado um "PE Stay".

Figura 2.1: Valor das ofertas por tipo de financiamento, 2006-2015

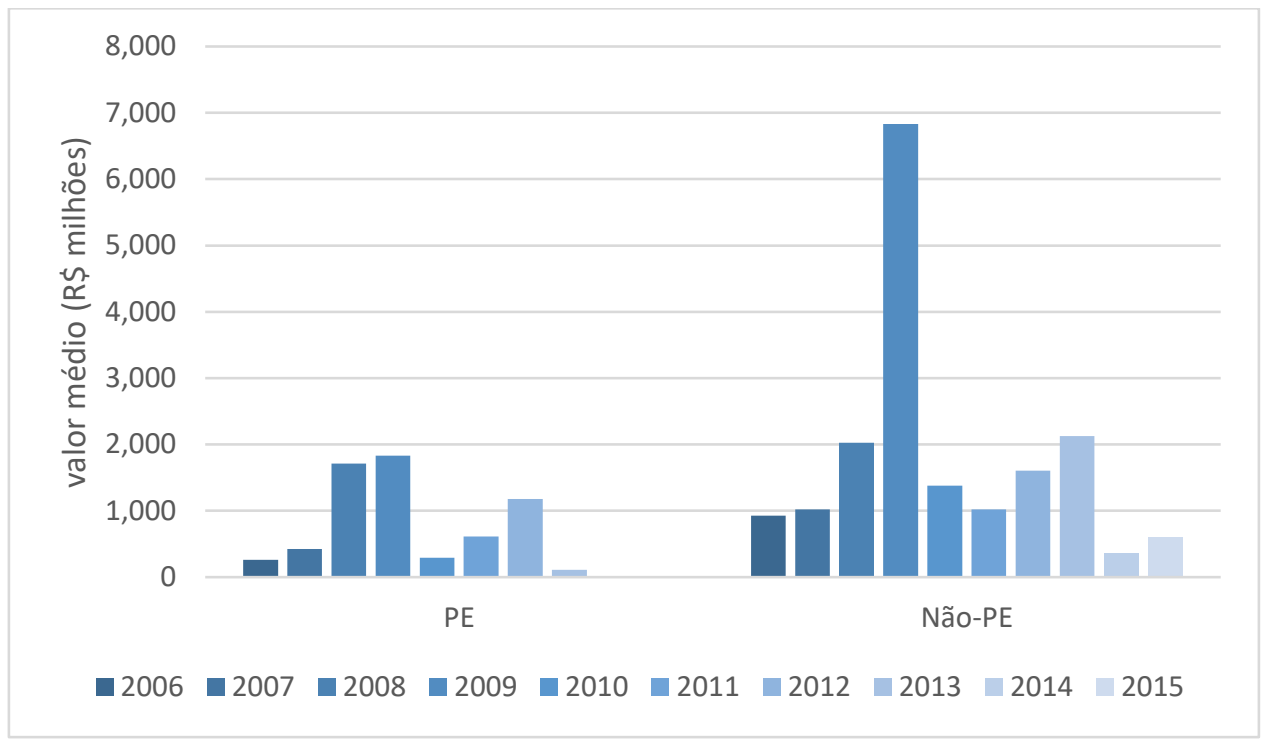

Para análise da performance dos tipos de IPO, foram catalogados os retornos dos papéis no primeiro dia de negociação na bolsa - que representa o "underpricing", ou seja, quanto de valor a empresa deixou na mesa no momento de sua venda - assim como a variação do papel da abertura até seu $252^{\circ}$ dia de negociação ( $1^{\circ}$ ano), que neste estudo é considerado como o retorno de longo prazo das ofertas, utilizado para medir a performance dessas emissões.

Para análise do nível de governança, foram obtidas as classificações das empresas na BM\&FBovespa, na qual a classificação Novo Mercado foi considerada representativa de alto nível de governança (valor 1), enquanto as demais classificações, para fins de modelagem, foram consideradas como um nível inferior de governança (valor 0).

Além disso, como forma de complementar a análise da governança, foram obtidos os percentuais de diretores independentes nos conselhos de administração das empresas no momento de sua oferta. Diversos estudos já tentaram observar a existência de relação entre um maior nível de independência entre o conselho e a 
diretoria de uma empresa e uma maior qualidade de governança e melhores resultados da empresa.

Fernandes (2008), por exemplo, aponta para uma baixa eficácia de membros independentes em conselhos, pois estes costumam receber salários acima da média e suas empresas apresentam maiores problemas de agência e consequentemente um menor alinhamento entre os interesses de acionistas e diretores.

Como forma de avaliar o nível de precificação de cada emissão, foram testadas duas proporções:

Enterprise Value/EBITDA: Essa métrica considera a razão entre o o valor de uma empresa e seu lucro antes de juros, impostos, depreciação e amortização, e permite analisar a empresa do ponto de vista de um comprador. De forma resumida, ela indica quanto tempo uma empresa precisaria funcionar para pagar o seu custo de aquisição; e

Price-to-Book: Essa métrica considera a razão entre o preço das ações de uma empresa (valor de mercado) e o seu valor contábil. Essa razão é expressada na forma de múltiplo e serve como uma indicação de quantas vezes os acionistas estão pagando pelos ativos líquidos da empresa. 


\section{$3 \quad$ Metodologia e Resultados}

\section{Calculo do excesso de retornos (CAR)}

A metodologia escolhida para comparar retornos foi a do CAR (Cumulative Abnormal Returns), que analisa o diferencial entre os retornos de cada ação e o do mercado para um mesmo período observado. O CAR no primeiro ano de negociações é calculado seguindo a sequência de equações abaixo.

Primeiramente, é mensurado o retorno diário de cada ação pela equação abaixo, na qual $P_{i, t}$ é o valor de fechamento da ação da empresa i no dia t, e $P_{i, t-1}$ é o seu valor de fechamento no dia anterior.

(3.1)

$$
R_{i, t}=\frac{P_{i, t}}{P_{i, t-1}}-1
$$

O excesso de retorno de cada ação em relação ao índice de mercado escolhido - no caso o IBOVESPA - é calculado seguindo a equação abaixo: (3.2)

$$
A R_{i, t}=R_{i, t}-R_{\text {mercado }, t}
$$

Por último, é calculado o excesso de retorno acumulado pela ação da empresa i em relação ao índice de mercado pelo período escolhido segundo a equação abaixo:

(3.3)

$$
C A R_{i, t}=\sum_{t=o}^{T} A R_{i, t}
$$


O período escolhido nesse trabalho para representar performance de longo prazo foi o CAR de 1 ano, ou seja, é calculada a formula acima para um período de 252 dias de negociação após a oferta primária de capital na bolsa.

$\mathrm{Na}$ tabela abaixo podem ser observados a média de retornos absolutos e do CAR (calculado conforme equações acima) no período de 1 ano após a abertura de capital na BM\&FBovespa, para os grupos de empresas separadas pelo ano de sua emissão de capital na bolsa e pela sua característica como investida de um fundo de private equity ou não.

Tabela 3.1: Retorno e CAR no primeiro ano de negociações, 2006-2015

\begin{tabular}{|c|c|c|c|c|c|c|}
\hline & \multicolumn{3}{|c|}{ Retorno $1^{\circ}$ ano } & \multicolumn{3}{|c|}{ CAR $1^{\circ}$ ano } \\
\hline & $\mathrm{PE}$ & Não-PE & Total & PE & Não-PE & Total \\
\hline 2006 & $36.3 \%$ & $74.2 \%$ & $51.5 \%$ & $-11.3 \%$ & $18.8 \%$ & $0.7 \%$ \\
\hline 2007 & $-21.4 \%$ & $-41.7 \%$ & $-28.2 \%$ & $-60.7 \%$ & $-67.3 \%$ & $-62.9 \%$ \\
\hline 2008 & $-25.6 \%$ & $-18.5 \%$ & $-22.1 \%$ & $-10.1 \%$ & $12.4 \%$ & $1.2 \%$ \\
\hline 2009 & $21.9 \%$ & $31.4 \%$ & $27.6 \%$ & $2.1 \%$ & $20.9 \%$ & $13.4 \%$ \\
\hline 2010 & $33.6 \%$ & $42.4 \%$ & $39.8 \%$ & $37.4 \%$ & $31.0 \%$ & $32.9 \%$ \\
\hline 2011 & $11.9 \%$ & $21.1 \%$ & $13.9 \%$ & $12.8 \%$ & $27.1 \%$ & $16.0 \%$ \\
\hline 2012 & $22.2 \%$ & $-11.8 \%$ & $-0.5 \%$ & $31.1 \%$ & $-4.0 \%$ & $7.7 \%$ \\
\hline 2013 & $20.4 \%$ & $24.4 \%$ & $23.6 \%$ & $20.9 \%$ & $19.7 \%$ & $19.9 \%$ \\
\hline 2014 & - & $25.9 \%$ & $25.9 \%$ & - & $33.9 \%$ & $33.9 \%$ \\
\hline 2015 & - & $-8.4 \%$ & $-8.4 \%$ & - & $-0.5 \%$ & $-0.5 \%$ \\
\hline Total & $0.2 \%$ & $10.8 \%$ & $5.1 \%$ & $-27.3 \%$ & $-4.9 \%$ & $-16.9 \%$ \\
\hline
\end{tabular}

Com exceção das emissões primárias realizadas durante os anos de 2007, 2010, 2012 e 2013, nos demais períodos as emissões de capital por empresas investidas de fundos de private equity obtiveram médias de CAR inferiores aos seus pares que não contavam com esse tipo de investimento. Nos anos de 2014 e 2015 não houveram emissões por empresas investidas de fundos de private equity, inviabilizando a comparação nesses períodos.

Na média ponderada, portanto, como podemos observar na tabela acima, as emissões primárias de capital realizadas por empresas investidas de fundos de private equity apresentaram CAR inferior às não investidas num horizonte de negociação de 1 ano após a abertura.

Para atestar este resultado, é modelada na seção 4 deste trabalho uma regressão econométrica que visa analisar a significância do investimento de fundos 
de private equity no CAR de 1 ano das ofertas primárias de capital na bolsa brasileira.

\section{Outliers}

Esta mesma série de CAR apresenta alguns resultados expressivos, que categorizamos como outliers na tabela abaixo. Foram assim consideradas as empresas com excesso de retorno superior a $50 \%$ (positivo) ou inferior a $-50 \%$ (negativo).

Tabela 3.2: Outliers (CAR <> 50\%) na série do CAR, 2006-2015

\begin{tabular}{clrr}
\hline \multirow{2}{*}{ PE } & Emissões & Positivo & \multicolumn{2}{c}{ Negativo } \\
\cline { 3 - 4 } & Retorno Abnormal Médio & 1 & 17 \\
\hline \multirow{2}{*}{ Não-PE } & Emissões & $62 \%$ & $-98 \%$ \\
\cline { 2 - 4 } & Retorno Abnormal Médio & 6 & 8 \\
\end{tabular}

Podemos observar que as emissões Não-PE tiveram número similar de outliers positivos e negativos (6 vs. 8), assim como retornos abnormais médios de nível mais similar (+66\% vs. $-90 \%)$.

Já nas emissões cujas empresas eram investidas por fundos de Private Equity, há um peso consideravelmente maior de outliers negativos (1 vs. 17) assim como em seu nível de retornos médios (+62\% vs. $-98 \%)$.

\section{Cálculo do Excesso de Retornos - Análise Setorial}

Conforme fora mencionado na introdução deste trabalho, a comparação entre a performance na bolsa de emissões de empresas investidas por fundos de private equity em relação às não investidas é algo que já fora estudado na literatura, para diferentes intervalos temporais, bolsas e tipos de emissões, de forma que este estudo visa agregar mais observações a estas análises. 
Tendo em vista os resultados observados neste trabalho, entretanto, ficou aberta a questão da possibilidade de haver um viés de seleção que impacte os resultados obtidos acima: talvez fundos de private equity tenham investido em setores que foram desfavorecidos no intervalo temporal analisado, já que este engloba algumas crises relevantes; ou, talvez, simplesmente comparar o retorno de uma empresa com o do mercado inteiro seja injusto devido às peculiaridades de cada setor.

Com base nessa observação, foi criada uma nova medida para análise de retornos: o CAR setorial.

A série de emissões foi dividida em 6 setores diferentes, e seus retornos foram analisados contra o retorno médio do setor em que a empresa se enquadra. Para a criação das séries de retornos de cada setor, foram utilizados como base de dados os índices setoriais divulgados pela BM\&FBovespa em seu website.

$\mathrm{Na}$ tabela abaixo podem ser observados os 6 setores em que foram divididas as empresas e como estavam distribuídas as emissões consideradas por este trabalho - aquelas ocorridas entre 2006 e 2015 na BM\&FBovespa.

Tabela 3.3: Concentração setorial das ofertas primárias de capital, 2006-2015

\begin{tabular}{lrrr} 
& PE & Não-PE & Total \\
\cline { 2 - 4 } Utilidade & $2 \%$ & $7 \%$ & $4 \%$ \\
Materiais & $2 \%$ & $5 \%$ & $3 \%$ \\
Industrial & $8 \%$ & $5 \%$ & $6 \%$ \\
Financeiro & $28 \%$ & $43 \%$ & $35 \%$ \\
Consumo & $55 \%$ & $34 \%$ & $45 \%$ \\
Energia & $6 \%$ & $7 \%$ & $6 \%$ \\
\hline
\end{tabular}

É interessante observar que as ofertas de capital feitas por investidas de fundos de private equity foram fortemente concentradas em empresas do setor de Consumo, ao passo que a maior concentração dentre aquelas que não possuíam fundos de private equity como investidores se deu no setor Financeiro. 
Figura 3.1: Emissões por Setor, 2006-2015

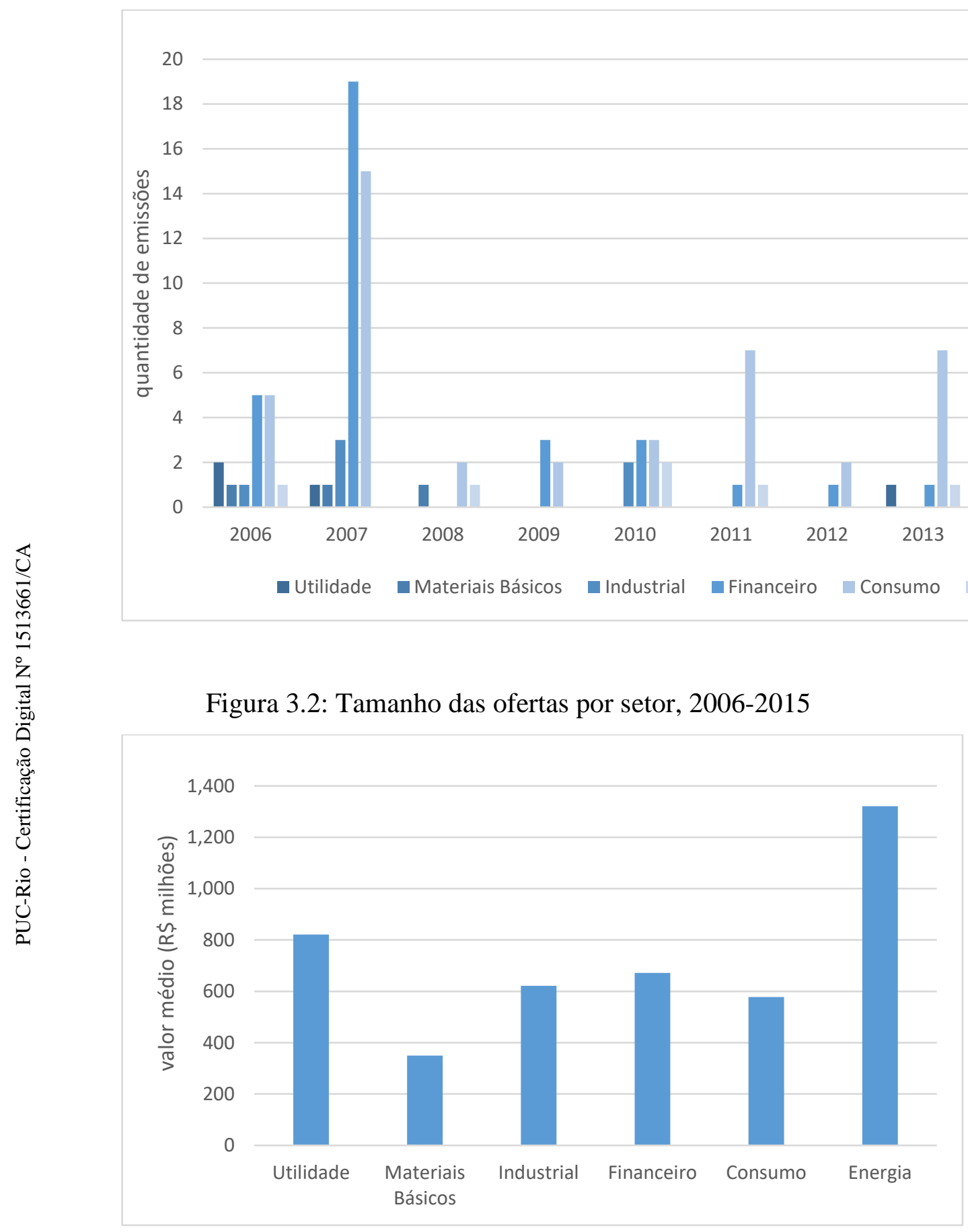

Para a obtenção do excesso de retornos em relação ao setor de cada uma das empresas, foi feito cálculo semelhante ao realizado anteriormente para o CAR, conforme equações abaixo: 
Primeiramente, é mensurado o retorno diário de cada ação pela equação abaixo, na qual $P_{i, t}$ é o valor de fechamento da ação da empresa i no dia t, e $P_{i, t-1}$ é o seu valor de fechamento no dia anterior.

(3.4)

$$
R_{i, t}=\frac{P_{i, t}}{P_{i, t-1}}-1
$$

O excesso de retorno de cada ação em é calculado em relação ao índice de mercado escolhido. Desta vez, é utilizado o índice setorial equivalente ao setor da empresa i. A equação é calculada conforme abaixo:

(3.5)

$$
A R s_{i, t}=R_{i, t}-R_{\text {setor } i, t}
$$

Por último, é calculado o excesso de retorno acumulado pela ação da empresa i em relação ao índice setorial equivalente pelo período escolhido segundo a equação abaixo:

(3.6)

$$
C A R s_{i, t}=\sum_{t=o}^{T} A R s_{i, t}
$$

O período escolhido nesse trabalho para representar performance de longo prazo foi o CAR setorial de 1 ano, ou seja, é calculada a formula 3.6 para um período de 252 dias de negociação após a oferta primária de capital na bolsa.

$\mathrm{Na}$ tabela abaixo podem ser observados as médias do CAR setorial (calculado conforme equações acima) no período de 1 ano após a abertura de capital na BM\&FBovespa, para os grupos de empresas separadas pelo ano de sua emissão de capital na bolsa e pela sua característica como investida de um fundo de private equity ou não.

Tabela 3.4: CAR Setorial no $1^{\circ}$ ano de negociações, 2006-2015

\begin{tabular}{rrr}
\hline PE & Não-PE & Total \\
\hline $5.8 \%$ & $33.6 \%$ & $19.7 \%$
\end{tabular}




\begin{tabular}{rrrr}
$\mathbf{2 0 0 7}$ & $-47.3 \%$ & $-51.3 \%$ & $-48.6 \%$ \\
$\mathbf{2 0 0 8}$ & $-7.4 \%$ & $29.3 \%$ & $10.9 \%$ \\
$\mathbf{2 0 0 9}$ & $4.2 \%$ & $20.0 \%$ & $13.7 \%$ \\
$\mathbf{2 0 1 0}$ & $19.9 \%$ & $11.3 \%$ & $13.9 \%$ \\
$\mathbf{2 0 1 1}$ & $0.3 \%$ & $14.7 \%$ & $3.5 \%$ \\
$\mathbf{2 0 1 2}$ & $3.7 \%$ & $-31.8 \%$ & $-20.0 \%$ \\
$\mathbf{2 0 1 3}$ & $7.6 \%$ & $14.2 \%$ & $12.9 \%$ \\
$\mathbf{2 0 1 4}$ & n.a. & $10.8 \%$ & $10.8 \%$ \\
$\mathbf{2 0 1 5}$ & n.a. & $14.9 \%$ & $14.9 \%$ \\
\hline Total & $\mathbf{- 2 3 . 4 \%}$ & $\mathbf{- 4 . 5 \%}$ & $-\mathbf{- 1 4 . 4 \%}$ \\
\hline
\end{tabular}

Assim como na análise do CAR absoluto, na análise do CAR setorial as emissões primárias de capital realizadas por empresas investidas de fundos de private equity apresentaram performance inferior às não investidas, num horizonte de negociação de 1 ano após a abertura.

Um aspecto positivo para as emissões realizadas por empresas investidas de fundos de private equity foi que elas apresentaram uma média de CAR menos negativa na análise setorial, se aproximando mais dos resultados obtidos pelas não investidas.

Observando ano a ano, entretanto, nota-se uma mudança no resultado de 2013, que foi mais favorável às empresas não investidas por fundos de private equity - o oposto do observado na análise do CAR absoluto.

O CAR setorial, portanto, chega a resultados semelhantes aos encontrados no CAR absoluto, indicando que empresas investidas por fundos de private equity tiveram performance inferior aos seus pares no período observado. Para atestar este resultado, é modelada na seção 4 deste trabalho uma regressão econométrica que visa analisar a significância do investimento de fundos de private equity no CAR setorial de 1 ano das ofertas primárias de capital na bolsa brasileira.

Numa separação dos resultados por setor, podemos chegar a interessantes observações.

\begin{tabular}{|c|c|c|c|c|c|c|}
\hline \multirow[b]{3}{*}{ Utilidade } & \multicolumn{3}{|c|}{ Emissões Primárias de Capital } & \multicolumn{3}{|c|}{ CAR Setorial $1^{\circ}$ ano } \\
\hline & PE & Não-PE & Total & PE & Não-PE & Total \\
\hline & 1 & 3 & 4 & $-2.4 \%$ & $-69.2 \%$ & $-52.5 \%$ \\
\hline Materiais & 1 & 2 & 3 & $-11.8 \%$ & $37.7 \%$ & $21.2 \%$ \\
\hline Industrial & 4 & 2 & 6 & $-27.8 \%$ & $-7.5 \%$ & $-21.0 \%$ \\
\hline Financeiro & 14 & 20 & 34 & $-19.1 \%$ & $-10.0 \%$ & $-13.8 \%$ \\
\hline Consumo & 29 & 15 & 44 & $-30.8 \%$ & $9.6 \%$ & $-16.3 \%$ \\
\hline
\end{tabular}




\begin{tabular}{lrrrrrr} 
Energia & 3 & 3 & 6 & $12.3 \%$ & $5.8 \%$ & $9.0 \%$ \\
\hline Total & $\mathbf{5 2}$ & $\mathbf{4 5}$ & $\mathbf{9 7}$ & $\mathbf{- 2 3 . 4 \%}$ & $\mathbf{- 4 . 5 \%}$ & $\mathbf{- 1 4 . 4 \%}$ \\
\hline
\end{tabular}

Tabela 3.5: Quantidade de emissões e CAR separados por setores

O setor de consumo, que apresenta uma das maiores concentrações para ambos os tipos de emissões, apresentou resultados muito diferentes quando havia ou não o investimento de fundos de private equity, ao passo que no setor financeiro, o segundo maior em termos de concentração, os dois grupos apresentaram retornos mais semelhantes.

Com tal dicotomia apresentada acima, buscamos modelar regressões econométricas para melhor avaliar o impacto dos setores de consumo e financeiro nas características de uma empresa no momento de sua oferta primária de capital. Tais resultados podem ser encontrados na seção 4 .

\section{Performance no primeiro dia (underpricing)}

Um fenômeno comum quando se trata de ofertas primárias de capital na bolsa é o do underpricing, que representa a variação de preço, geralmente positiva, de uma ação em seu primeiro dia de negociações na bolsa. Diversos estudos analisaram esse fenômeno buscando explicações para tal comportamento. Booth e Chua (1996) concluem que a demanda por dispersão de propriedade do emissor e os custos de informação são dois dos principais fatores responsáveis por tal ocorrência, enquanto Loughran e Ritter (2002) argumentam que o underpricing subiu nos anos 2000 em virtude de um menor foco na maximização dos resultados do IPO, devido tanto a uma maior ênfase na cobertura da pesquisa quanto à alocações de IPOs às contas de corretagem pessoal dos executivos das empresa emissoras.

Com o objetivo de acrescentar a essa base literária, foi feita neste trabalho uma análise dos resultados das empresas de ambos grupos (PE e Não-PE) em seu primeiro dia de negociações. 
A metodologia escolhida para comparar retornos foi, em sintonia com as anteriores, a do CAR - Cumulative Abnormal Returns, que analisa o diferencial entre os retornos de cada ação e o do mercado para um mesmo período observado. $\mathrm{O}$ CAR no primeiro dia de negociações é calculado seguindo a sequência de equações abaixo.

Primeiramente, é mensurado o retorno cada ação pela equação abaixo, na qual $P_{i, t}$ é o valor de fechamento da ação da empresa i no dia $\mathrm{t}$ - nesse caso, em seu primeiro dia de negociações na BM\&FBovespa - e $P_{i, t-1}$ é o valor de fechamento da ação da empresa i no dia anterior a abertura de suas negociações, equivalente ao valor de cada ação na oferta primária de capital.

(3.7)

$$
R_{i, t}=\frac{P_{i, t}}{P_{i, t-1}}-1
$$

O excesso de retorno de cada ação em relação ao índice de mercado escolhido - no caso o IBOVESPA - é calculado seguindo a equação abaixo: (3.8)

$$
A R_{i, t}=R_{\mathrm{i}, t}-R_{\text {mercado }, t}
$$

Por último, é calculado o excesso de retorno acumulado pela ação da empresa i em relação ao índice de mercado pelo período escolhido segundo a equação abaixo:

$$
C A R_{i, 1}=\sum_{0}^{1} A R_{t}=A R_{i, 1}
$$

Neste caso, como o período escolhido nesse trabalho para analisar o underpricing foi de 1 dia após a oferta primária de capital na bolsa, o CAR passa a ser igual ao AR calculado na equação anterior.

Na tabela abaixo podem ser observados a média de retornos absolutos e do CAR (calculado conforme equações acima) no período de 1 dia após a abertura de capital na BM\&FBovespa, para os grupos de empresas separadas pelo ano de sua 
emissão de capital na bolsa e pela sua característica como investida de um fundo de private equity ou não.

Tabela 3.6: Retorno e CAR no primeiro dia de negociações, 2006-2015

\begin{tabular}{|c|c|c|c|c|c|c|}
\hline & \multicolumn{3}{|c|}{ Retorno $1^{\circ}$ dia } & \multicolumn{3}{|c|}{ CAR $1^{\circ}$ dia } \\
\hline & PE & Não-PE & Total & PE & Não-PE & Total \\
\hline 2006 & $4.1 \%$ & $7.7 \%$ & $5.6 \%$ & $3.7 \%$ & $6.1 \%$ & $4.7 \%$ \\
\hline 2007 & $2.4 \%$ & $0.6 \%$ & $1.8 \%$ & $1.6 \%$ & $0.6 \%$ & $1.3 \%$ \\
\hline 2008 & $-5.8 \%$ & $1.6 \%$ & $-2.1 \%$ & $-5.8 \%$ & $1.8 \%$ & $-2.0 \%$ \\
\hline 2009 & $1.1 \%$ & $4.1 \%$ & $2.9 \%$ & $-1.7 \%$ & $3.0 \%$ & $1.2 \%$ \\
\hline 2010 & $8.4 \%$ & $-2.5 \%$ & $0.8 \%$ & $6.6 \%$ & $-3.2 \%$ & $-0.3 \%$ \\
\hline 2011 & $4.5 \%$ & $-3.2 \%$ & $2.8 \%$ & $4.6 \%$ & $-3.1 \%$ & $2.9 \%$ \\
\hline 2012 & $-5.6 \%$ & $5.2 \%$ & $1.6 \%$ & $-6.4 \%$ & $5.3 \%$ & $1.4 \%$ \\
\hline 2013 & $-2.5 \%$ & $-0.2 \%$ & $-0.6 \%$ & $-2.0 \%$ & $-1.3 \%$ & $-1.4 \%$ \\
\hline 2014 & - & $2.4 \%$ & $2.4 \%$ & - & $2.4 \%$ & $2.4 \%$ \\
\hline 2015 & - & $12.7 \%$ & $12.7 \%$ & - & $12.3 \%$ & $12.3 \%$ \\
\hline Total & $2.6 \%$ & $1.5 \%$ & $2.1 \%$ & $2.0 \%$ & $1.0 \%$ & $1.5 \%$ \\
\hline
\end{tabular}

Conforme previsto o underpricing ocorre, na média, em ambos os grupos tanto em termos de retornos quanto no CAR.

Tanto na análise dos retornos quanto do CAR, observamos que as empresas investidas por fundos de private equity tiveram performance superior em seu primeiro dia de negociações, ou seja, maior underpricing. Seguindo as explicações de Booth e Chua (1996) e de Loughran e Ritter (2002), tal fenômeno poderia ser exacerbado por uma maior pressa em vender por parte dos fundos de private equity, mas compensado pelos menores custos de informação, dado que essas empresas tendem a oferecer um maior conhecimento de mercado às suas investidas. Assim, vemos essa diferença pouco relevante entre o underpricing em cada um dos grupos.

É observada posteriormente neste trabalho, através de modelos econométricos, a significância desses resultados.

\section{Variáveis explicativas - uma análise das características das empresas}

Além da performance na bolsa, este trabalho também visa analisar os aspectos qualitativos das empresas que ofertaram ações na BM\&FBovespa entre 2006 e 2015 conforme sua classificação como PE ou Não-PE. 
Abaixo, pode-se observar a mediana dos resultados encontrados dentre cada um dos grupos para as características selecionadas para análise.

Tabela 3.7: Características qualitativas no momento da oferta primária

\begin{tabular}{|c|c|c|c|c|c|}
\hline & $\begin{array}{c}\text { Novo } \\
\text { Mercado } \\
\end{array}$ & $\begin{array}{c}\text { Diretores } \\
\text { Independentes }\end{array}$ & Alavancagem & EV/Ebitda & $\begin{array}{c}\text { Price-to- } \\
\text { Book }\end{array}$ \\
\hline PE & $80.8 \%$ & $36.36 \%$ & $2.4 x$ & $8.1 x$ & $1.9 x$ \\
\hline Não-PE & $75.6 \%$ & $40.00 \%$ & $1.4 x$ & $14.4 x$ & $2.0 \mathrm{x}$ \\
\hline Total & $78.4 \%$ & $38.75 \%$ & $1.8 \mathrm{x}$ & $9.7 x$ & $1.9 x$ \\
\hline
\end{tabular}

Segundo os dados analisados no período em questão, no momento de suas ofertas primárias de capital, o grupo das empresas investidas por fundos de private equity apresentava i) uma concentração maior de integrantes do Novo Mercado, representando um maior nível de governança, ao mesmo tempo em que tinham um menor percentual de diretores independentes em seus conselhos; ii) um nível de alavancagem (Dívida Líquida/Ebitda) consideravelmente maior (2.4x vs. 1.4x); e iii) uma menor precificação em ambas as métricas selecionadas para análise (EV/Ebitda e Price-to-Book).

Analisamos e testamos estes resultados na próxima seção, onde são modeladas regressões econométricas que visam analisar a significância dos investimentos de fundos de private equity, assim como outros fatores, nas características observadas acima. 


\section{Estimação do Modelo}

Tendo em mãos os resultados acima, e partindo das séries de dados coletadas, foram montadas regressões econométricas para tentar constatar fatores que ajudem a explicar os CAR obtidos e examinar quais os diferenciais observáveis entre emissões realizadas por empresas investidas de fundos de PE e de empresas não-investidas.

\section{Excesso de retorno acumulado (CAR) no primeiro ano}

O primeiro ponto analisado na seção anterior foi a performance no primeiro ano de negociações, medida pelo CAR de 1 ano.

Pelos retornos absolutos e CAR observados, vimos que emissões primárias realizadas por empresas investidas de fundos de private equity apresentaram retornos (0.2\% vs. $10.8 \%)$ e CAR (-27.3\% vs. $-4.9 \%)$ inferiores aos daqueles que não apresentam esse tipo de investidor.

Abaixo, modelamos uma regressão econométrica que visa atestar a significância desses resultados e o impacto de cada coeficiente no CAR de 1 ano.

A regressão é modelada conforme a seguinte equação:

(4.1)

$$
\begin{aligned}
C A R_{i} & =\alpha+\beta_{1} \times \text { Oferta }+\beta_{2} \times \text { Governança }+\beta_{3} \times \text { Alavancagem } \\
& +\beta_{4} \times \text { Precificação }+\beta_{5} \times \text { PE Backed }+\beta_{6} \times P E \text { Stay }
\end{aligned}
$$

Onde CAR é o excesso de retornos acumulados em relação ao Ibovespa; Oferta é o tamanho da oferta; Governança é o nível de governança; Alavancagem é a razão Dívida Líquida/Ebitda; Precificação pode ser a razão EV/Ebitda ou a razão Price-to-Book; PE Backed representa a presença desse tipo de investidor no 
momento do IPO; e PE Stay representa empresas nas quais esses investidores continuaram como acionistas após a oferta de capital.

Os resultados podem ser observados na tabela 4.1, abaixo:

Tabela 4.1: Regressão linear do CAR no primeiro ano de negociações, 20062015

\begin{tabular}{lrrr}
\hline & $(1)$ & $(2)$ & $(3)$ \\
Tamanho Oferta & $\mathbf{0 . 0 0}$ & $\mathbf{0 . 0 0}$ & $\mathbf{0 . 0 0}$ \\
& $-(0.514)$ & $-(0.017)$ & $-(0.695)$ \\
Governança & $\mathbf{0 . 1 7}$ & $\mathbf{0 . 2 3}$ & $\mathbf{0 . 2 6}$ \\
& $(1.042)$ & $(1.505)$ & $(1.240)$ \\
Dívida Liquida/EBITDA & -0.01 & -0.01 & $-\mathbf{0 . 0 6}$ \\
& $-(1.001)$ & $-(1.082)$ & $-(2.300)^{* *}$ \\
EV/EBITDA & & & 0.00 \\
& & & $(2.005)^{* *}$ \\
Price-to-Book & & -0.03 & \\
& & $-(3.926)^{* * *}$ & \\
PE Backed & $-\mathbf{0 . 2 0}$ & -0.30 & $-\mathbf{0 . 1 2}$ \\
& $-(1.766)^{*}$ & $-(2.822)^{* * *}$ & $-(0.875)$ \\
PE Stay & $\mathbf{0 . 4 7}$ & 0.56 & $\mathbf{0 . 4 5}$ \\
& $(1.457)$ & $-(1.908)^{*}$ & $(1.010)$ \\
\hline R2 & $\mathbf{0 . 1 1}$ & $\mathbf{0 . 3 0}$ & $\mathbf{0 . 2 3}$ \\
Observações & 64 & 63 & 45 \\
\hline Estatísticas T entre parênteses & & & \\
*** representa significância estatística a 1\% & & & \\
$* *$ representa significância estatística a 5\% & & & \\
* representa significância estatística a 10\% & & &
\end{tabular}

A tabela 4.1 mostra os resultados da regressão do CAR de um ano das firmas nas características observáveis. As variáveis de interesse são as dummies indicando se há fundos de private equity entre os acionistas da firma (PE Backed), e se o fundo permanece como acionista após o IPO (PE Stay). A segunda e terceira colunas adicionam Price-to-Book e EV/EBITIDA como controles, respectivamente. Como não temos EV/EBITIDA para todas as firmas, nossa amostra diminui bastante $(\mathrm{N}=45)$ na última especificação, o que pode reduzir consideravelmente o poder do teste. Por isso, a coluna 2 é a especificação favorita.

Os resultados da coluna 2 mostram que IPOs de firmas com private equity tem CAR $30 \%$ menor, mesmo controlando para as características observadas da firma e do IPO, e a estimativa é significante ao nível de 1\%. Por outro lado, parece 
haver uma diferença grande entre as firmas em que o fundo de private equity sai e as firmas em que o fundo continua entre os acionistas. A dummy PE Stay apresenta coeficiente de 0.56 , e este resultado é significante ao nível de $10 \%$.

Esse resultado traz um indício de que fundos de private equity teriam sim, a capacidade de trazer excessos de retornos positivos a empresas que abrem capital na bolsa - quando eles mantêm seu investimento nas mesmas após a emissão. Tal condição pode implicar, dentre muitas possibilidades, que as empresas não foram capazes de manter o padrão de governança após a saída desses investidores, ou também que os fundos não conseguiram deixar mecanismos de controle que auxiliassem as empresas a manter este nível de governança após a sua saída.

\section{Retorno no primeiro ano ajustado por setor}

Na seção 3 observamos, através da construção e análise do CAR Setorial, que as empresas investidas por fundos de private equity obtiveram retornos inferiores em seu primeiro ano de negociação na bolsa em relação aos seus pares que não contavam com esse tipo de investidor - apesar de isto ter ocorrido de forma menos acentuada que na análise do CAR absoluto.

Abaixo, modelamos uma regressão econométrica que visa atestar a significância desses resultados e o impacto de cada coeficiente no CAR setorial.

A regressão é modelada conforme a seguinte equação:

(4.2)

$$
\begin{aligned}
\text { CARs }_{i} & =\alpha+\beta_{1} \times \text { Oferta }+\beta_{2} \times \text { Governança }+\beta_{3} \times \text { Alavancagem } \\
& +\beta_{4} \times \text { Precificação }+\beta_{5} \times \text { PE Backed }+\beta_{6} \times \text { PE Stay }
\end{aligned}
$$

Onde CARs é o excesso de retornos acumulados setorial; Oferta é o tamanho da oferta; Governança é o nível de governança; Alavancagem é a razão Dívida Líquida/Ebitda; Precificação pode ser a razão EV/Ebitda ou a razão Price-to-Book; PE Backed representa a presença desse tipo de investidor no momento do IPO; e PE Stay representa empresas nas quais esses investidores continuaram como acionistas após a oferta de capital. 
Os resultados podem ser observados na tabela 4.2, abaixo:

Tabela 4.2: Regressão linear do CAR Setorial no primeiro ano de negociações, 2006-2015

\begin{tabular}{|c|c|c|c|}
\hline & (1) & (2) & (3) \\
\hline \multirow[t]{2}{*}{ Tamanho Oferta } & 0.00 & 0.00 & 0.00 \\
\hline & $(1.040)$ & $(-0.704)$ & $(1.670)^{*}$ \\
\hline \multirow[t]{2}{*}{ Governança } & 0.13 & 0.14 & 0.12 \\
\hline & $(2.343)^{* *}$ & $(0.902)$ & $(1.569)$ \\
\hline \multirow[t]{2}{*}{ Dívida Liquida/EBITDA } & 0.01 & -0.02 & -0.01 \\
\hline & $(0.961)$ & $-(1.821)^{*}$ & $-(0.505)$ \\
\hline \multirow[t]{2}{*}{ EV/EBITDA } & & & 0.00 \\
\hline & & & $(0.672)$ \\
\hline \multirow[t]{2}{*}{ Price-to-Book } & & -0.03 & \\
\hline & & $-(4.611)^{* * *}$ & \\
\hline \multirow[t]{2}{*}{ PE Backed } & 0.00 & -0.24 & 0.02 \\
\hline & $-(0.044)$ & $-(2.215)^{* *}$ & $(0.288)$ \\
\hline \multirow[t]{2}{*}{ PE Stay } & 0.17 & 0.29 & 0.14 \\
\hline & (1.098) & (1.006) & (0.865) \\
\hline $\mathbf{R 2}$ & 0.10 & 0.35 & 0.16 \\
\hline Observações & 89 & 61 & 43 \\
\hline
\end{tabular}

A tabela 4.2 mostra, agora pelo modelo, que um fundo de private equity dentre os investidores de uma empresa no momento de sua emissão primária de capital é um fator que tem um impacto negativo significante em seu CAR de 1 ano. Pela regressão 2, a variável PE Backed apresentou coeficiente -0.24 a um nível de significância de $5 \%$.

Assim como na regressão do CAR absoluto, nesta foram também registrados coeficientes positivos em todas as regressões para a variável PE Stay, apesar de nenhum dos coeficientes apresentar nível de significância igual ou inferior a $10 \%$.

Outro resultado que chama atenção é o coeficiente negativo a $1 \%$ de significância para a variável price-to-book na regressão 2. Tal valor indica que, para este intervalo, quanto maior a precificação de IPO de uma empresa em relação ao 
seu valor contábil, menor o seu CAR Setorial observado no primeiro ano de negociação na bolsa.

Além disso, podemos observar que o grau de alavancagem de uma empresa no momento de sua emissão primária também atua na direção de um menor CAR Setorial no primeiro ano de negociação, apresentando coeficiente de -0.02 a um nível de significância de $10 \%$ na regressão 2 .

Conforme vimos na tabela 3.7 da seção 3, empresas investidas por fundos de private equity tendem a ter alavancagem consideravelmente superior às que não contam com esse tipo de investidor (2.4x vs. 1.4x), o que pode ajudar a explicar os menores resultados apresentados pelas empresas investidas por esse tipo de fundo. Por outro lado, as empresas do grupo PE apresentaram uma razão price-to-book inferior, o que segunda a regressão contribuiria para um CAR setorial superior, mas a diferença muito pequena (1.9x vs. 2.0x) não foi suficiente para garantir um resultado melhor para o grupo $\mathrm{PE}$.

\section{Retorno no primeiro dia: underpricing}

$\mathrm{Na}$ seção 3 observamos, através da construção e análise do CAR do underpricing, que as empresas investidas por fundos de private equity obtiveram retornos superiores em seu primeiro dia de negociação na bolsa em relação aos seus pares que não contavam com esse tipo de investidor - ou seja, apresentaram maior underpricing.

Abaixo, modelamos uma regressão econométrica que visa atestar a significância desses resultados e estudar o impacto de cada coeficiente no CAR do underpricing.

A regressão é modelada conforme a seguinte equação:

(4.3)

$$
\begin{gathered}
\text { CARu }_{i}=\alpha+\beta_{1} \times \text { Oferta }+\beta_{2} \times \text { Governança }+\beta_{3} \times \text { Alavancagem } \\
+\beta_{4} \times \text { Precificação }+\beta_{5} \times \text { PE Backed }+\beta_{6} \times P E \text { Stay }
\end{gathered}
$$


Onde CARu é o excesso de retornos acumulados no primeiro dia de negociações; Oferta é o tamanho da oferta; Governança é o nível de governança; Alavancagem é a razão Dívida Líquida/Ebitda; Precificação pode ser a razão EV/Ebitda ou a razão Price-to-Book; PE Backed representa a presença desse tipo de investidor no momento do IPO; e PE Stay representa empresas nas quais esses investidores continuaram como acionistas após a oferta de capital.

Os resultados podem ser observados na tabela 4.3, abaixo:

Tabela 4.3: Regressão linear do CAR no primeiro dia de negociações, 20062015

\begin{tabular}{lrrr}
\hline & $(1)$ & $(2)$ & $(3)$ \\
Tamanho Oferta & $\mathbf{0 . 0 0}$ & $\mathbf{0 . 0 0}$ & $\mathbf{0 . 0 0}$ \\
& $(1.102)$ & $(1.010)$ & $(1.385)$ \\
Governança & $\mathbf{0 . 0 3}$ & $\mathbf{0 . 0 3}$ & $\mathbf{0 . 0 6}$ \\
& $(1.127)$ & $(1.025)$ & $(1.585)$ \\
Dívida Liquida/EBITDA & $\mathbf{0 . 0 0}$ & $\mathbf{0 . 0 0}$ & $\mathbf{0 . 0 0}$ \\
& $-(0.798)$ & $-(0.795)$ & $-(0.757)$ \\
EV/EBITDA & & & $\mathbf{0 . 0 0}$ \\
& & & $(0.602)$ \\
Price-to-Book & & $\mathbf{0 . 0 0}$ & \\
& & $(0.493)$ & \\
PE Backed & $\mathbf{0 . 0 1}$ & $\mathbf{0 . 0 1}$ & $\mathbf{0 . 0 1}$ \\
& $(0.382)$ & $(0.493)$ & $(0.206)$ \\
PE Stay & $-\mathbf{0 . 0 6}$ & $-\mathbf{0 . 0 6}$ & $-\mathbf{0 . 0 8}$ \\
& $-(1.004)$ & $-(1.025)$ & $-(1.032)$ \\
\hline R2 & $\mathbf{0 . 0 7}$ & $\mathbf{0 . 0 7}$ & $\mathbf{0 . 1 5}$ \\
Observações & 64 & 63 & 45 \\
\hline Estatísticas T entre parênteses & & & \\
$* * *$ representa significância estatística a 1\% & & & \\
$* *$ representa significância estatística a 5\% & & & \\
$*$ representa significância estatística a 10\% & & &
\end{tabular}

Apesar de os coeficientes concordarem com a observação de que investimento por fundos de private equity implica em maior underpricing nos IPOs, em nenhuma das regressões estimadas tal coeficiente apresentou significância igual ou inferior aos $10 \%$ que consideramos como mínimo.

$\mathrm{Na}$ verdade, como podemos observar na tabela acima, nenhuma das regressões apresentou qualquer variável com tal nível de significância, indicando 
que nenhuma das variáveis selecionadas neste trabalho tem boa capacidade preditiva em relação ao fenômeno de underpricing.

Apesar de não significante, vale observar que a variável PE Stay apresentou coeficientes negativos, indicando que quando os fundos de private equity não se desfizeram das suas ações no IPO, a empresa apresentou um retorno inferior em seu dia inaugural de negociações.

Já o índice de governança, conforme observado acima, apresentou coeficientes positivos nas 3 regressões. Este coeficiente representa a quantidade de empresas listadas no Novo Mercado, e a maior liquidez desses ativos provavelmente indica o motivo para tal resultado.

\section{Características}

Por último, além de sua performance, também analisamos na seção 3 os aspectos estruturais e qualitativos das empresas que fizeram ofertas primárias de capital na BM\&FBovespa entre 2006 e 2015.

O objetivo desta etapa é analisar comparativamente as características das empresas investidas por fundos de private equity e disto entender que outros tipos de valor, que não apenas a performance, estes fundos trazem para suas investidas.

Abaixo, modelamos regressões econométricas que visam atestar a significância dos resultados observados na seção anterior e o impacto de cada coeficiente em cada uma das variáveis analisadas.

As regressões são modeladas conforme a seguinte equação:

(4.4)

$$
Y_{i}=\alpha+\beta_{1} \times P E \text { Backed }_{i}+\beta_{2} \times \text { PE Stay }
$$

Onde $Y_{i}$ denota uma das seguintes variáveis dependentes: Novo Mercado (nível de governança); Diretores Independentes (\%); Alavancagem (Dívida Líquida/Ebitda); e EV/Ebitda e Price-to-Book (ambas de precificação).

Além disso, Tamanho Oferta representa o montante financeiro da emissão; PE Backed representa a presença desse tipo de investidor no momento do IPO; e PE 
Stay representa empresas nas quais esses investidores continuaram como acionistas após a oferta de capital.

Os resultados podem ser observados na tabela 4.4, abaixo:

Tabela 4.4: Regressão linear das características no momento da oferta primária, 2006-2015

\begin{tabular}{|c|c|c|c|c|c|}
\hline & Novo Mercado & Diretores Indep. & Alavancagem & EV/Ebitda & Price-to-Book \\
\hline \multirow[t]{2}{*}{ Tamanho Oferta } & 0.00 & 0.00 & 0.00 & 0.00 & 0.00 \\
\hline & $-(0.543)$ & $-(1.004)$ & $-(0.584)$ & $-(0.332)$ & $-(1.055)$ \\
\hline \multirow[t]{2}{*}{ PE Backed } & 0.06 & 0.37 & 1.13 & -19.69 & 2.75 \\
\hline & (0.654) & $(0.060)$ & (1.082) & $-(1.823)^{*}$ & (0.262) \\
\hline \multirow[t]{2}{*}{ PE Stay } & -0.15 & -3.95 & 0.68 & -3.98 & -6.44 \\
\hline & $-(0.609)$ & $-(0.192)$ & $(0.230)$ & $-(0.110)$ & $-(0.217)$ \\
\hline R2 & 0.01 & 0.03 & 0.03 & 0.08 & 0.01 \\
\hline Observações & 97 & 44 & 64 & 46 & 94 \\
\hline \\
\hline & \multicolumn{5}{|c|}{$* * *$ representa significância estatística a $1 \%$} \\
\hline \multicolumn{6}{|c|}{ ** representa significância estatística a 5\% } \\
\hline \multicolumn{6}{|c|}{ * representa significância estatística a $10 \%$} \\
\hline \multicolumn{6}{|c|}{ A tabela acima confirma o que fora visto na seção 3 , com a variável $\mathrm{PE}$} \\
\hline \multirow{2}{*}{\multicolumn{6}{|c|}{ d apresentando coeficientes positivos em ambos indicadores de governança e }} \\
\hline & & & & & \\
\hline \multicolumn{6}{|c|}{ licador de alavancagem, ao passo que apresenta um coeficiente negativo de - } \\
\hline \multicolumn{6}{|c|}{9 a um nível de significância de $10 \%$ para o indicador de precificação } \\
\hline \multicolumn{6}{|c|}{ Ebitda. } \\
\hline
\end{tabular}

Berger e Udell (1998) argumentam que empresas menores, por serem empreendimentos de dono, tendem a apresentar menos dos típicos conflitos entre acionistas e diretoria que afetam escolhas de estrutura de capital em grandes corporações. Entretanto, segundo os autores, outros fatores são relevantes a essas empresas como a aversão a risco de seus donos e seu incentivo a preferir capitalização através do endividamento em vez de novos acionistas, com o objetivo de manter o controle da firma.

Como podemos notar na tabela abaixo, para o intervalo estudado, os fundos de private equity investiram, na média, em empresas consideravelmente menores e 
que fizeram emissões também menores. Tal diferença, em concordância ao fenômeno observado por Berger e Udell, pode explicar o maior grau de alavancagem observado na série, assim como o coeficiente positivo visto na regressão acima.

Figura 4.1: Valor das ofertas por tipo de financiamento, 2006-2015

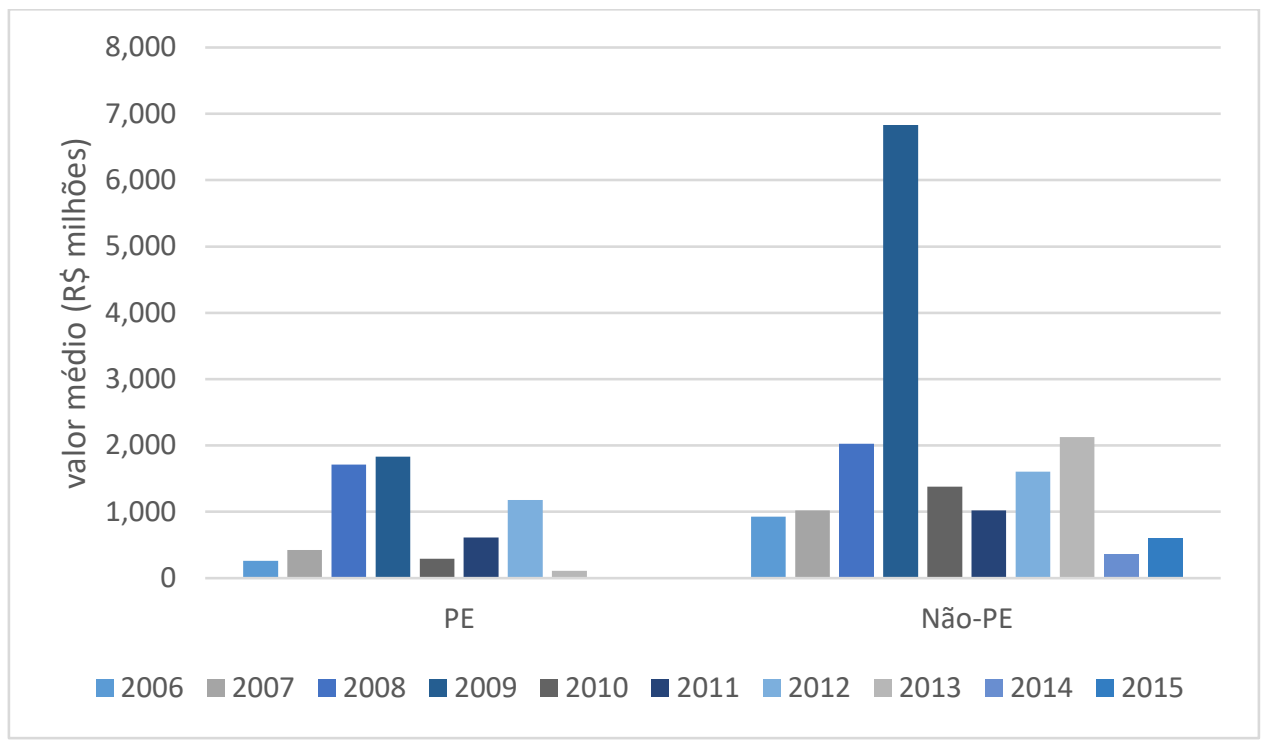

\section{ii. Governança}

Berger e Udell argumentam também que empresas menores tendem a apresentar uma maior opacidade em suas informações disponíveis, já que muitas no início de seu ciclo de crescimento não possuem demonstrações financeiras auditadas, ativos comerciais facilmente avaliados e têm pouco histórico de reembolso sobre os quais fornecedores externos podem confiar. Segundo eles, mesmo após um período maior de experiência, as pequenas empresas permanecem opacas em relação às grandes empresas.

Assim sendo, é louvável o resultado acima indicando que empresas investidas por fundos de private equity apresentam maiores índices de governança em ambos indicadores analisados, por serem essas empresas em média, como vimos anteriormente, menores que seus pares não-PE.

iii. Valuation 
Como já vimos anteriormente, ofertas primárias de empresas investidas por fundos de PE tendem a apresentar um maior underpricing, isto é, têm maior valorização que seus pares não-PE. Tal observação é condizente com a de que empresas de fundos PE apresentaram um múltiplo EV/EBITDA significativamente (a 10\%) inferior. Afinal, quanto menor o valor de uma ação no momento de sua emissão, mais espaço esta ação tem para se valorizar no seu primeiro dia de negociação.

Vismara, Signori e Paleari (2015) argumentam que a seleção de empresas comparáveis à emissora apresentadas por bancos de investimento ao subscreverem IPOs costumam ter avaliações mais altas do que as escolhidas para serem publicadas em seus relatórios de pesquisa após o IPO, especialmente no mercado americano. Argumentam ainda que, por esta apresentação de pares sobre-avaliados fazer com que as ações do emissor aparentem ter um preço conservador em seu IPO, tal seleção de pares resulta em maior underpricing e menor desempenho a longo prazo dos IPOs.

Como observamos acima que os IPOs das empresas investidas por fundos PE apresentam maior underpricing e menor retorno de longo prazo que as empresas não-PE, é possível que de alguma forma parte desses componentes observados pelos autores estejam também presentes na série analisada por este trabalho.

\section{Características - Setores de Consumo e Financeiro}

Anteriormente observamos que, no intervalo estudado, fundos de PE apresentaram uma maior pré-disposição a investimentos no setor de consumo, ao passo que os IPOs "Não-PE” tiveram maior concentração no setor financeiro.

Dada essa dicotomia, fez-se uma análise das características específicas destes setores para isolar a possibilidade de o maior endividamento dos IPOs PE ocorrer devido à sua maior concentração em um setor específico.

Abaixo, modelamos regressões econométricas que visam atestar a significância dos resultados observados na seção 3 e o impacto em cada uma das variáveis analisadas. 
As regressões são modeladas conforme a seguinte equação:

(4.5)

$Y_{i}=\alpha+\beta_{1} \times P E$ Backed $_{i}+\beta_{2} \times P E$ Stay $_{i}+\beta_{3} \times$ Consumo $_{i}+\beta_{4} \times$ Financeiro $_{i}$

Onde $Y_{i}$ denota uma das seguintes variáveis dependentes: Novo Mercado (nível de governança); Diretores Independentes (\%); Alavancagem (Dívida Líquida/Ebitda); e EV/Ebitda e Price-to-Book (ambas de precificação).

Além disso, Tamanho Oferta representa o montante financeiro da emissão; PE Backed representa a presença desse tipo de investidor no momento do IPO; PE Stay representa empresas nas quais esses investidores continuaram como acionistas após a oferta de capital; Consumo é uma dummy que representa empresas que fazem parte do setor de consumo; e Financeiro, uma dummy para o setor financeiro.

Os resultados podem ser observados na tabela 4.5, abaixo:

Tabela 4.5: Regressão linear das características no momento da oferta primária incluindo dummies para os setores de Consumo e Financeiro, 2006-2015

\begin{tabular}{lrrrrr}
\hline & Novo Mercado & Diretores Indep. & Alavancagem & EV/Ebitda & Price-to-Book \\
\cline { 2 - 6 } Tamanho Oferta & & & & & \\
& $\mathbf{0 . 0 0}$ & $\mathbf{0 . 0 0}$ & $\mathbf{0 . 0 0}$ & $\mathbf{0 . 0 0}$ & $\mathbf{0 . 0 0}$ \\
PE Backed & $-(0.339)$ & $-(1.419)$ & $-(0.539)$ & $-(0.095)$ & $-(1.029)$ \\
& $\mathbf{0 . 0 2}$ & $\mathbf{0 . 5 2}$ & $\mathbf{1 . 5 9}$ & -19.31 & $\mathbf{5 . 0 4}$ \\
PE Stay & $(0.281)$ & $(0.085)$ & $(1.502)$ & $-(1.837)^{*}$ & $(0.470)$ \\
& $-\mathbf{0 . 2 2}$ & $-\mathbf{2 . 1 3}$ & $\mathbf{1 . 2 3}$ & $-\mathbf{1 . 0 3}$ & $-\mathbf{3 . 3 6}$ \\
Setor Consumo & $-(0.884)$ & $-(0.104)$ & $(0.416)$ & $-(0.030)$ & $-(0.112)$ \\
& $\mathbf{0 . 0 8}$ & $\mathbf{3 . 1 2}$ & -0.90 & $\mathbf{9 . 2 8}$ & $\mathbf{4 . 8 4}$ \\
Setor Financeiro & $(0.702)$ & $(0.410)$ & $-(0.701)$ & $(0.712)$ & $(0.344)$ \\
& -0.11 & 13.65 & 1.54 & $\mathbf{4 2 . 4 5}$ & $\mathbf{1 9 . 5 2}$ \\
& $-(0.931)$ & $(1.524)$ & $(1.004)$ & $(2.375)^{* *}$ & $(1.349)$ \\
\hline R2 & $\mathbf{0 . 0 5}$ & $\mathbf{0 . 0 9}$ & $\mathbf{0 . 0 8}$ & $\mathbf{0 . 2 0}$ & $\mathbf{0 . 0 4}$ \\
Observações & 97 & 44 & 64 & 46 & 94 \\
\hline Estatísticas T entre parênteses & & & & & \\
*** representa significância estatística a 1\% & & & & \\
** representa significância estatística a 5\% & & & & \\
* representa significância estatística a $10 \%$ & & & &
\end{tabular}

Conforme pode ser observado na regressão, o setor de consumo (de maior concentração dos IPOs PE) tem impacto negativo no endividamento de uma empresa, enquanto o financeiro (de maior concentração dos IPOs Não-PE) tem impacto positivo na alavancagem. 
Podemos ver ainda que a variável PE Backed apresenta coeficiente de -19.31 para o múltiplo de precificação EV/Ebitda a um nível de significância de $10 \%$, enquanto o setor financeiro apresenta coeficiente positivo de 42.45 a significância de 5\% para esta mesma variável. Enquanto o primeiro destes dois resultados fica em linha com o observado na regressão anterior, sem os setores, o resultado positivo para o setor financeiro ajuda a explicar a maior precificação média de IPOs Não-PE, já que $43 \%$ destes (vs. 28\% dos PE) foram de empresas do setor financeiro.

No mais, esta nova regressão pouco agrega ao já visto na regressão original de análise das características das emissões. 


\section{Conclusões}

O objetivo primário deste estudo foi de analisar retornos e características das emissões primárias de capital realizadas na BM\&FBovespa entre 2006 e 2015, como meio de observar os diferenciais trazidos por fundos de private equity para suas empresas investidas.

Quando analisado o período de 1 ano de negociações após a oferta primária de capital, ficou constatado na base de dados e testado pelas regressões que as empresas investidas por fundos de private equity tiveram retornos $(0.2 \%$ vs. $10.8 \%)$ e CAR (-27.3\% vs. -4.9\%) inferiores aos das empresas que não tinham esse tipo de investidor.

Com o objetivo de expurgar qualquer viés de seleção, em que fundos de PE poderiam ter, por exemplo, investido em setores errados nos anos analisados, foi construída uma série de CAR setorial utilizando os índices setoriais da BM\&FBovespa. Apesar de diminuir a diferença de performance, as empresas investidas de fundos PE ainda assim apresentaram CAR inferior (-23.4\% vs. $-4.5 \%)$.

Interessante foi notar que quando os fundos de private equity mantiveram seus investimentos após a abertura de capital, as empresas apresentaram CAR superiores a quando havia o desinvestimento, para ambas as metodologias anteriores. Entretanto, foram muitos poucos os casos na série para que pudessem ser tiradas conclusões mais definitivas sobre este fenômeno, e seria um tema muito interessante a ser estudado daqui a alguns anos, quando houverem novos casos como estes.

Foi analisado também o underpricing e constatado que as empresas PE mostraram números timidamente superiores tanto de retorno (2.6\% vs. $1.5 \%)$ quanto de CAR (2.0\% vs. $1.0 \%)$. Isso vai em linha com a literatura, que indica que uma maior pressa em vender por parte dos fundos de private equity poderia contribuir positivamente para o underpricing, ao passo que os menores custos de informação, 
dado que os fundos tendem a oferecer um maior conhecimento de mercado às suas investidas, diluem tal impacto positivo.

Em adição às análises da performance desses investimentos, foram construídas diversas séries de variáveis qualitativas para tentar observar que outros tipos de características marcantes as empresas investidas por fundos de private equity carregam.

Pelo trabalho aqui feito para a série analisada, as empresas investidas por fundos de private equity apresentaram melhores níveis de governança, maior grau de alavancagem e menores múltiplos de precificação no momento de suas ofertas primárias.

Apesar de a bolsa brasileira apresentar números de ofertas em quantidade bem inferior a outros mercados mais desenvolvidos, este trabalho foi capaz de trazer novos e significativos dados a análise local para o estudo dos efeitos que fundos de private equity são capazes de trazer às suas empresas investidas no país.

Com o passar dos anos, tendo novas observações e uma maturação da indústria no país, é possível que surjam novos resultados e fenômenos que valham ser revisitados e estudados. 


\section{Referências bibliográficas}

(1) Megginson, William L., and Kathleen A. Weiss. "Venture capitalist certification in initial public offerings." The Journal of Finance 46.3 (1991): 879-903.

(2) Hogan, Karen M., Gerard T. Olson, and Richard J. Kish. "A comparison of reverse leveraged buyouts and original initial public offers: factors impacting their issuance in the IPO market." Financial Review 36.3 (2001): 1-18.

(3) Lee, Peggy M., and Sunil Wahal. "Grandstanding, certification and the underpricing of venture capital backed IPOs." Journal of Financial Economics 73.2 (2004): 375-407.

(4) Levis, Mario. "The performance of private equity-backed IPOs." Financial Management 40.1 (2011): 253-277.

(5) Minardi, Andrea Maria Accioly Fonseca, Guilherme Lopes Ferrari, and Pedro Carvalho AraújoTavares. "Performances of Brazilian IPOs backed by private equity." Journal of Business Research 66.3 (2013): 448-455.

(6) Tavares, Pedro Carvalho Araujo, and Andrea Maria Accioly Fonseca Minardi. "Does Private Equity Investment Work as a Quality Certification for IPOs in Brazil?." (2010).

(7) BOURRAT, Sylvain, Guillaume WOLFF, and Florencio LOPEZ de SILANES. "Underpricing and Long-Term Performance of Private-Equity Backed IPOs compared to Non-Private-Equity Backed IPOs A French perspective." Unpublished master's Thesis). EDHEC Business School, Roubaix, France (2013).

(8) Lammi, Juho. "The long-run performance of PE and VC backed IPOsEvidence from the Nordic and German markets." (2016).

(9) Fernandes, Nuno. "EC: Board compensation and firm performance: The role of "independent" board members." Journal of multinational financial management 18.1 (2008): 30-44. 
(10) Booth, James R., and Lena Chua. "Ownership dispersion, costly information, and IPO underpricing." Journal of Financial Economics 41.2 (1996): 291-310.

(11) Loughran, Tim, and Jay R. Ritter. "Why has IPO underpricing changed over time?." (2002).

(12) Berger, Allen N., and Gregory F. Udell. "The economics of small business finance: The roles of private equity and debt markets in the financial growth cycle." Journal of banking \& finance 22.6 (1998): 613-673.

(13) Vismara, Silvio, Andrea Signori, and Stefano Paleari. "Changes in underwriters' selection of comparable firms pre-and post-IPO: Same bank, same company, different peers." Journal of Corporate Finance 34 (2015): 235250 . 